\title{
HSP27, ALDH6A1 and Prohibitin Act as a Trio-biomarker to Predict Survival in Late Metastatic Prostate Cancer
}

\author{
SUNG YONG CHO ${ }^{1}$, SUKI KANG ${ }^{2}$, DONG SU KIM ${ }^{3}$, HYUNG JIN NA ${ }^{3}$, \\ YE JIN $\mathrm{KIM}^{3}$, YOUNG DEUK CHOI ${ }^{4}$ and NAM HOON $\mathrm{CHO}^{2,5,6}$ \\ ${ }^{1}$ Department of Urology, Yonsei University College of Medicine, \\ Korea and Inje University College of Medicine, Goyang, Republic of Korea; \\ ${ }^{2}$ Department of Pathology, Yonsei University College of Medicine, Seoul, Republic of Korea; \\ ${ }^{3}$ Genomine Inc., Pohang, Republic of Korea; \\ ${ }^{4}$ Department of Urology, Yonsei University College of Medicine, Seoul, Republic of Korea; \\ ${ }^{5}$ Severance Biomedical Science, Yonsei University College of Medicine, Seoul, Republic of Korea; \\ ${ }^{6}$ Brain Korea 21 PLUS Project for Medical Science, Yonsei University, Seoul, Republic of Korea
}

\begin{abstract}
Background/Aim: The aim of this study was to evaluate the usefulness of biomarkers related to prostate cancer metastasis and survival of patients. Materials and Methods: Proteomics were used for detecting significant differences in protein expression among normal prostate, localized prostate cancer and metastatic cancer using 2-dimensional gel electrophoresis and mass spectrometry. mRNA expression was then examined in order to further confirm significant differences in protein expression. A total of 7 proteins were found to be differentially expressed. Immunochemistry (IHC), was also used to confirm the levels of expression of the 7 proteins in prostate cancer. Survival analysis using the candidate markers was finally performed in 98 metastatic prostate cancer patients according to IHC results. Results: In metastatic lesions, proteomic analysis indicated that heat shock protein (HSP) 27, prohibitin, glutathione $S$-transferase 1 , fibrinogen $\beta$ chain, and aldehyde dehydrogenase $6 A 1$ were up-regulated, while $\alpha 1$ antitrypsin, and HSP 60 were down-regulated. IHC revealed that HSP 27, ALDH6Al and prohibitin were highly specific to metastatic tumor cells. HSP27 and prohibitin appeared more strongly in the incipient stage of cancer than metastatic
\end{abstract}

Correspondence to: Nam Hoon Cho, Department of Pathology, Yonsei University College of Medicine, 250 Seongsanno, Seodaemun-gu, Seoul, 120-152, Republic of Korea. Tel: +82 222281767, Fax: +82 23620860, e-mail: cho1988@yuhs.ac; Young Deuk Choi, Department of Urology, Yonsei University College of Medicine, Yonsei University Health System, 50-1 Yonsei-ro, Seodaemun-gu, Seoul, 120-752, Republic of Korea. Tel: +82 222282317, Fax: +82 23122538, e-mail: youngd74@yuhs.ac

Key Words: Prostate cancer, metastasis, biomarker. cancer, and ALDH6Al was significantly reduced in metastatic cancer $(p<0.01)$. Of all proteins, phohibitin had the highest value in predicting survival. However, all three proteins were a stronger marker than each one separately. Conclusion: Trio-biomarker composed of HSP27, ALDH6Al and prohibitin may predict survival of metastatic prostate cancer patients.

Since there are no biomarkers to predict late metastasis in prostate cancer patients, unnecessary diagnostic and therapeutic algorithms have been non-selectively used. With the exception of the Gleason score and the TNM Classification of Malignant Tumors (TNM) stage, no valid prognostic biomarkers have been identified to predict poor prognosis (1).

The genetic mechanisms of PCa development and progression are still largely unknown, and molecular data on $\mathrm{PCa}$ are relatively scarce and poorly understood. Identifying predictive markers, known as biomarkers, for metastatic $\mathrm{PCa}$ will be important for improving treatment outcome and survival. Biomarkers can support therapeutic decisions and may enable for more focused therapies. Currently, many prostate cancer biomarkers have been identified and are under investigation. Biomarkers for screening prostate cancer have been extensively studied since PSA testing and some of these have been suggested to be used in a clinical setting (2). However, biomarkers related to the progress of local prostate cancer are less studied. Despite an established mode of treatment for localized $\mathrm{PCa}$, patients with high-risk PCa, including hormonal refractory $\mathrm{PCa}$ or disseminated cancer have no promising therapy $(3,4)$. In fact, no valid biomarkers have been proposed, even for localized PCa. It is very urgent to identify novel biomarkers for prostate cancer progression, with the ultimate aim of predicting those cases that will likely result in a poor outcome. The aim of 


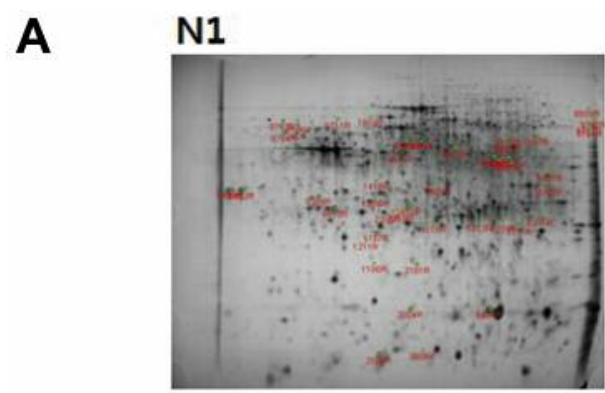

N2

N3
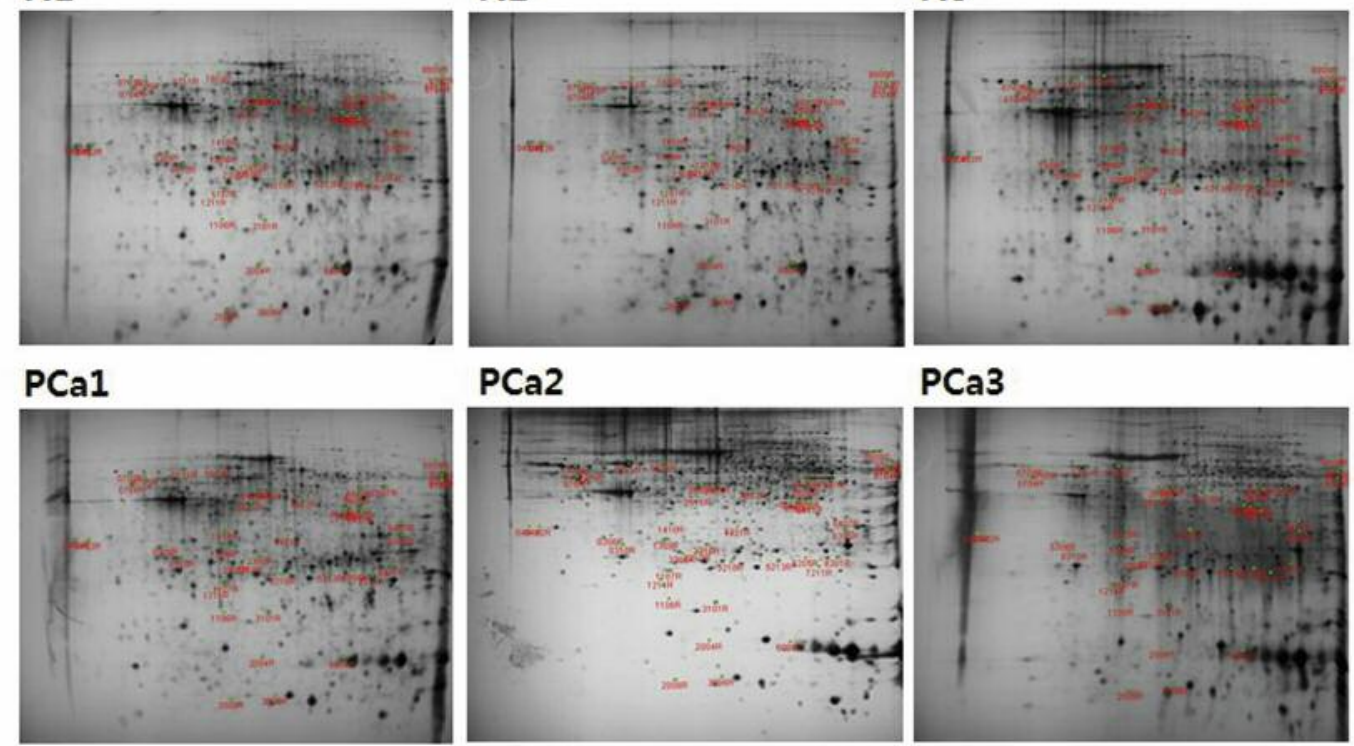

\section{$\mathrm{PCa} 2$}

\section{$\mathrm{PCa} 3$}
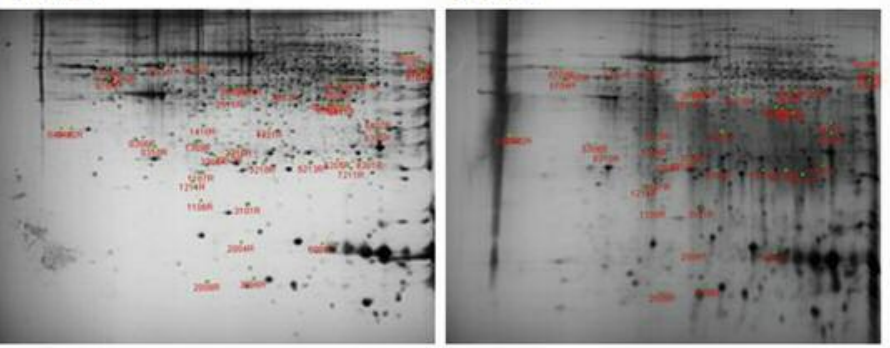

mPCa1

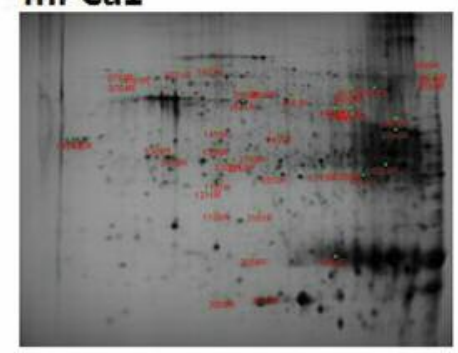

\section{$\mathrm{mPCa} 2$}

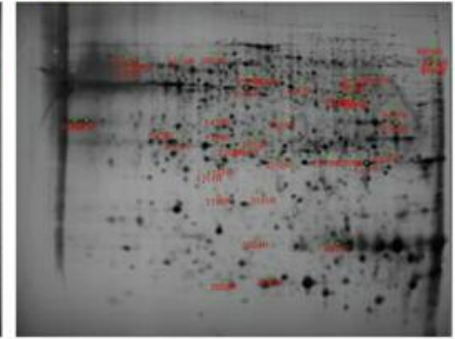

B

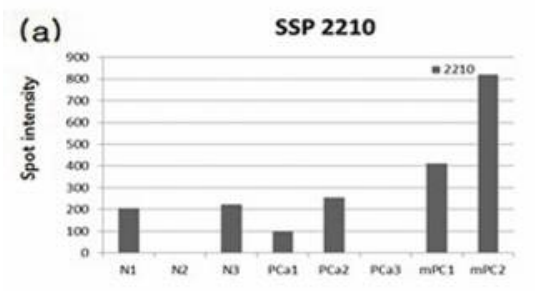

(b)
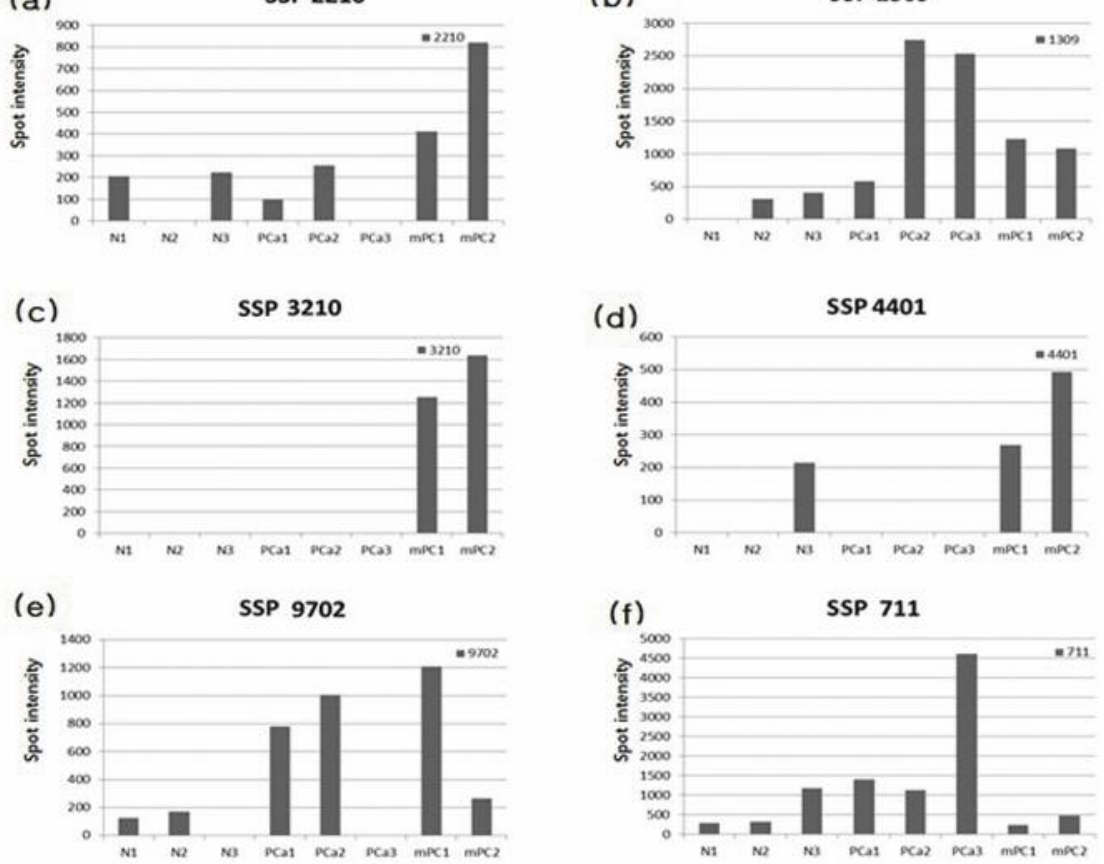
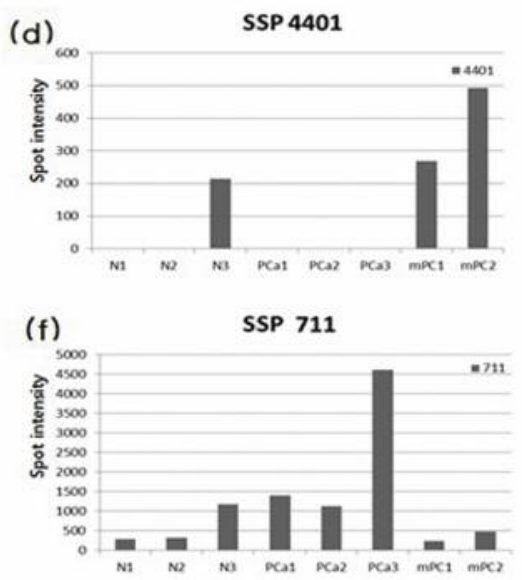

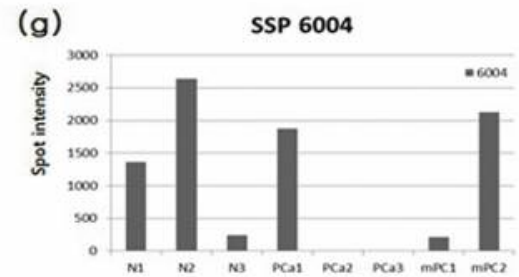

Figure 1. Continued 

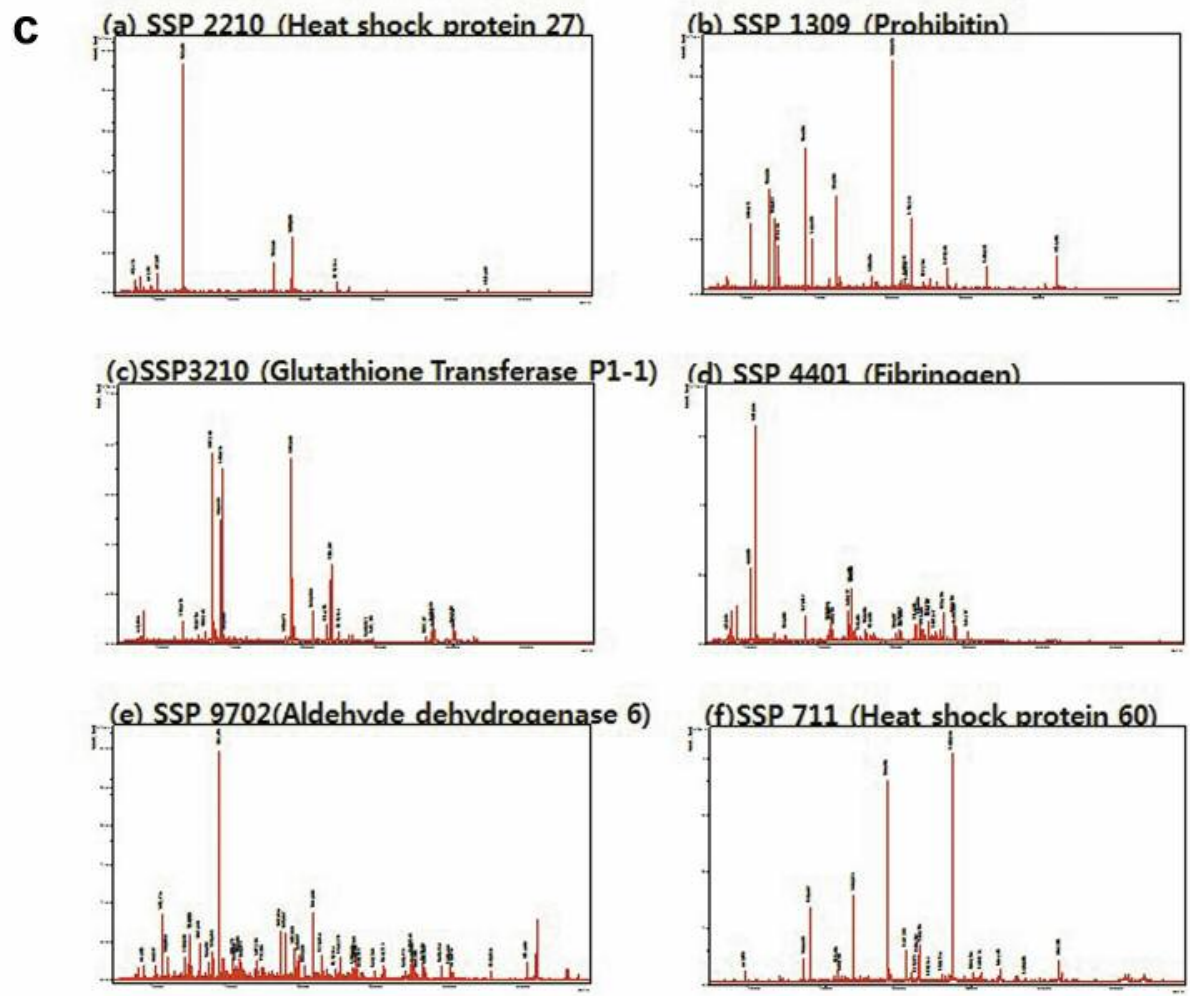

(g) SSP 6004 (Alpha-1-antitrypsin)

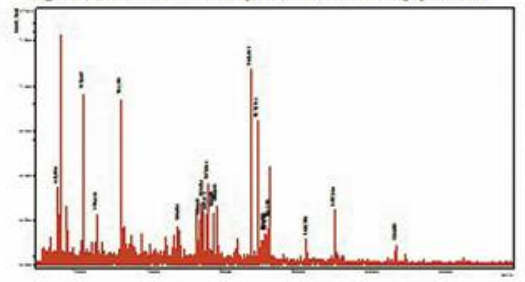

Figure 1. Proteomics analysis of normal, metastatic and localized prostate cancer tissue. A. Representative two-dimensional gel electrophoresis. N1-3: normal prostate tissues; PCa1-3: prostate cancer tissues; mPCa1-2: bone metastatic prostate cancer tissues. B. Differentially expressed protein spots from the 2-DE gels. Histogram depicting the intensity of spots. C. The candidate proteins were identified by peptide mass fingerprinting (chemically assisted MALDI-PSD spectra).

this study was to identify biomarkers predicting metastatic prostate cancer.

\section{Materials and Methods}

Sample preparation. First, frozen samples of 3 normal prostates, 3 localized prostate cancers, 2 bone metastatic prostate cancers (mPCa) were prepared for two-dimensional gel electrophoresis. Second, 9 formalin-fixed, paraffin-embedded (FFPE) samples (7 lung-metastatic prostate cancer tissue and 2 normal lung tissues) were prepared for mRNA validation. Specimens were obtained from Yonsei University College of Medicine (Seoul, Republic of Korea). Third, 8 paraffin-embedded tissues used for immunohistochemistry (IHC) were obtained from Abcam (Cambridge, UK). Finally, 98
mPCa patients were enrolled for clinomic validation that is the evaluation of the correlation between death and protein expression assessed by IHC.

\section{Proteomics}

Protein extraction. Tissue samples were homogenized using a Power Gen 125 (Fisher Scientific, Pittsburgh, PA, USA) in 2-DE lysis solution composed of $7 \mathrm{M}$ urea, $2 \mathrm{M}$ thiourea, 4\% (w/v) 3-((3cholamidopropy) dimethyammonio)-1-propanesulfonate (CHAPS), $1 \%(\mathrm{w} / \mathrm{v})$ dithiothreitol (DTT), $2 \%(\mathrm{v} / \mathrm{v})$ Pharmalyte, and $1 \mathrm{mM}$ benzamidine. Proteins were extracted by vortex-mixing for $30 \mathrm{~min}$ at room temperature followed by centrifugation at $15,000 \mathrm{xg}$ for $30 \mathrm{~min}$ at $15^{\circ} \mathrm{C}$. The supernatant was used for protein extraction. Protein concentrations of tissue extracts were determined by Bradford assay (5). 
Two-dimensional gel electrophoresis and image analysis. 2-DE was performed as previously described (6). Briefly, $200 \mu \mathrm{g}$ of protein extracts were separated in the first dimension by isoelectric focusing using an immobilized $\mathrm{pH}$ gradient (IPG) strip with a non-linear $\mathrm{pH}$ gradient of 4-10 (Genomine, Inc., Kyungbuk, Republic of Korea), followed by SDS-PAGE $(26 \times 20 \mathrm{~cm}$ format $)$ in the second dimension. Proteins were detected by alkaline silver staining. Image analysis and quantification of protein spots were performed using PDQuest software (Bio-Rad, Hercules, CA, USA). The amount of protein in each spot was normalized to the total valid spot intensity.

Protein profile analysis. Clustering of samples and generation of protein expression profiles were performed with Cluster and Tree View software (http://rana.lbl.gov/EisenSoftware) to analyze and display the differential pattern of protein expression. The statistical significance of the differences in average protein expression was determined with Mann-Whitney $U$-test. Spots with differences of $p<0.05$ were chosen for further investigation. Median centering for data adjustment and the default options of hierarchical clustering were applied using the uncentered correlation similarity matrix. The distance between the overall expression profiles was determined as described previously by summing all the spot intensity ratios. The resulting distance matrix was used to build neighbor-joining trees with the MEGA software package (http://www.megasoftware.net).

Protein identification by mass spectrometry. For protein identification, protein spots were excised, digested with trypsin (Promega, Madison, WI, USA), mixed with $\alpha$-cyano-4-hydroxycinnamic acid in $50 \%$ acetonitrile/0.1\% TFA, and subjected to MALDI-TOF (matrix-assisted laser desorption ionization time of flight) analysis (Ettan MALDI-TOF Pro, Amersham Biosciences, Piscataway, NJ, USA) as previously described (7). Spectra were collected from 350 shots per spectrum over the range $600-3000 \mathrm{~m} / \mathrm{z}$ and calibrated by two-point internal calibration using trypsin autodigestion peaks $(842.5099 \mathrm{~m} / \mathrm{z}$ and $2211.1046 \mathrm{~m} / \mathrm{z}$ ). The peak list was generated using Ettan MALDI-TOF Pro Evaluation Module (version 2.0.16). The threshold used for peakpicking was 5,000 for minimum resolution of monoisotopic mass and 2.5 for S/N. The ProFound program (http://prowl.rockefeller.edu/ prowl-cgi/profound.exe) was used to search the human NCBInr database (version 2010/04/01, 228540 entries) for protein identification. The following parameters were used for the database search: trypsin as the cleaving enzyme, a maximum of one missed cleavage, iodoacetamide (Cys) as a complete modification, oxidation (Met) as a partial modification, monoisotopic masses, and a mass tolerance of $\pm 0.1 \mathrm{Da}$. Peptide mass fingerprinting (PMF) acceptance criterion was probability scoring. Amino acid sequencebased protein identification by MALDI-post-source decay (PSD) spectra of selected $\mathrm{N}$-terminal derivatized peptides and the derivatization reactions were performed as previously described ( 8 , 9). For protein identification, the fragment masses obtained from MALDI-PSD were used to search the NCBInr database (version 2010-01-29, 10,386,837 entries) using Ettan MALDI-TOF Pro software (Sonar, version 2.0.16) or the protein identification search engine PepFrag (http://prowl.rockefeller. edu/prowl/pepfrag.html). Spectrum processing for peak detection was performed using Ettan MALDI-TOF Pro Evaluation Module (version 2.0.16).

mRNA validation

NanoString nCounter ${ }^{\circledR}$ gene expression system. Total RNA was extracted with RNeasy FFPE Kit (Qiagen, Hilden, Germany) from
FFPE tissue. Eight genes (HSP27, prohibitin, GSTP1, Fibrinogen $\beta$ chain, S100a4, A1AT, aldehyde dehydrogenase 6A1 (ALDH6A1), and HSP60) were analyzed using the NanoString nCounter ${ }^{\circledR}$ Gene Expression System (NanoString Technologies, Seattle, WA, USA) according to the manufacturer's protocol. The probe sets were designed and synthesized at NanoString Technologies. Two reference genes $(\beta$-actin and GAPDH) were analyzed for biological normalization purposes. Probes were hybridized to $100 \mathrm{ng}$ of total RNA for all targets simultaneously. Following hybridization, transcripts were quantitated using the NanoString nCounter ${ }^{\circledR}$ Digital Analyzer (10). Data were normalized for assay efficiency by multiplying each count by a positive normalization factor obtained for each sample. Raw NanoString counts for each gene were subjected to a technical normalization considering the counts obtained for positive control probe sets. After technical normalization, biological normalization using the two reference genes was performed (11).

Immunohistochemistry. FFPE samples were used for assessing expression of heat shock protein (HSP) 27, prohibitin, GSTP1, fibrinogen $\beta$ chain, S100a4, A1AT, ALDH6A1, and HSP 60 (Abcam) by IHC. In brief, 4- $\mu \mathrm{m}$ sections of paraffin-embedded tissues were deparaffinized and rehydrated. After treatment with $3 \%$ hydrogen peroxide for $10 \mathrm{~min}$ to block endogenous peroxidases, the sections were boiled in $10 \mathrm{mM}$ citrate buffer $(\mathrm{pH}$ 6.0) in a microwave for $20 \mathrm{~min}$. The sections were subsequently incubated at $4^{\circ} \mathrm{C}$ overnight with primary antibodies to the proteins listed above. After thorough rinsing in phosphate-buffered saline (PBS), the sections were processed using the DAKO LSAB streptavidin-biotin labeling kit, followed by staining with aminoethyl carbazole and counterstaining with Mayer's hematoxylin.

Patients. A total of $98 \mathrm{mPCa}$ patients were enrolled. The patients were divided into two groups. Patients of the first group were still alive, while patients of the other group had died from metastasis. Logistic regression analysis was performed to compare the two groups. Receiver operating characteristic (ROC) curves, sensitivity and specificity were also obtained.

Statistical analysis. The relationship between the protein marker and patient characteristics was analyzed by logistic regression and a Fisher's exact test. Clinomics results were analyzed by the R package (http://www.r-project.org) (Random forest, Classification tree).

\section{Results}

Biomarker Screening by $2 D$ proteomics. A total of 45 different protein-spots, showing a significant difference among mPCa (bone), localized PCa, and normal prostate were identified (Figure 1A), using peptide mass fingerprinting (PMF). Seven candidate protein-spots, five that were up-regulated and two that were down-regulated, were selected because of their significantly different fold change in expression among normal, cancer and bone metastatic tissue (Figure 1B and Table I). Subsequent informatics identified HSP27, prohibitin, Glutathione Stransferase 1 (GSTP1), fibrinogen $\beta$ chain, and aldehyde dehydrogenase 6 family A1 (ALDH6A1) as the proteins that were up-regulated more than 4-fold in $\mathrm{PCa}$ compared to the 
Table I. Proteins present in samples subjected to 2D-GE. The peptide profiles of the protein spots treated with trypsin were analyzed by MALDITOF MS. ProFound (http://129.85.19.192/profound_bin/WebProFound.exe) was used to search the protein database for protein identification using peptide mass fingerprinting (PMF). The mass and pI values specified are theoretically matched by a database search. a: observed; $b$ : theoretically calculated; $c$ : the rate of increase in intensity (average prostate cancer sample intensity/average prostate normal sample intensity); $d:$ the rate of increase in intensity (average metastasis bone sample intensity/average prostate tumor sample intensity); $e$ : the rate of increase in intensity (average metastasis bone sample intensity/average prostate cancer sample intensity).

\begin{tabular}{|c|c|c|c|c|c|c|c|c|c|}
\hline $\begin{array}{l}\text { Spot } \\
\text { no. }\end{array}$ & $\begin{array}{l}\text { Protein } \\
\text { name }\end{array}$ & $\begin{array}{c}\text { Accession } \\
\text { no. }\end{array}$ & $\begin{array}{l}\mathrm{pI}^{\mathrm{a} /} \\
\mathrm{pI}^{\mathrm{b}}\end{array}$ & $\begin{array}{l}\mathrm{MW}^{\mathrm{a}} / \mathrm{MW}^{\mathrm{b}} \\
(\mathrm{kDa})\end{array}$ & $\begin{array}{c}\text { Sequence } \\
\text { coverage }(\%)\end{array}$ & Score & $\begin{array}{l}\text { Fold } \\
\mathrm{PC} / \mathrm{N}^{\mathrm{c}}\end{array}$ & $\begin{array}{l}\text { Fold } \\
\mathrm{MB} / \mathrm{N}^{\mathrm{d}}\end{array}$ & $\begin{array}{c}\text { Fold } \\
\mathrm{MB} / \mathrm{PC}\end{array}$ \\
\hline 2210 & Heat shock protein 27 & gil662841 & $5.7 / 7.83$ & $40.7 / 22.43$ & 44 & 125 & 0.82 & 4.29 & 5.23 \\
\hline 1309 & Prohibitin & gil46360168 & $5.2 / 5.57$ & $48.6 / 29.86$ & 62 & 278 & 8.19 & 4.85 & 0.59 \\
\hline 3210 & $\begin{array}{c}\text { Chain A, glutathione } \\
\text { Transferase P1-1 }\end{array}$ & gil20664358 & $6.28 / 5.09$ & $36.8 / 23.43$ & 69 & 138 & 1.00 & 1444.20 & 1444.20 \\
\hline 4401 & $\begin{array}{l}\text { Chain } \mathrm{B} \text {, crystal structure } \\
\text { of recombinant human } \\
\text { fibrinogen fragment D }\end{array}$ & gil24987624 & $6.35 / 7.08$ & $50.3 / 36.33$ & 43 & 146 & 0.01 & 5.30 & 381.49 \\
\hline 9702 & $\begin{array}{l}\text { Aldehyde dehydrogenase } \\
6 \text { family, member A1, } \\
\text { isoform CRA_a }\end{array}$ & gil119601564 & $9.73 / 7.57$ & $91.6 / 49.95$ & 39 & 109 & 6.03 & 7.46 & 1.24 \\
\hline 711 & $\begin{array}{l}60 \mathrm{kDa} \text { heat shock } \\
\text { protein, mitochondrial }\end{array}$ & gil221042312 & $5.14 / 5.59$ & $98.7 / 60.18$ & 46 & 219 & 3.98 & 0.60 & 0.15 \\
\hline 6004 & $\begin{array}{l}\text { Alpha-1-antitrypsin } \\
\text { (aa 268-394) }\end{array}$ & gil7770183 & $7.34 / 8.93$ & 21.1/13.09 & 71 & 119 & 0.44 & 0.83 & 1.87 \\
\hline
\end{tabular}

normal gland (score >100: Figure 1C). A1AT (0.83-fold) and HSP60 (0.60-fold) were comparatively decreased in $\mathrm{mPCa}$ (Figure $1 \mathrm{C}$ and Table I).

Validation of surrogate peptides at the transcriptional level. To validate potential metastatic biomarkers, mRNA expression was performed using the NanoString analyzer. HSP27, prohibitin, GSTP1, fibrinogen $\beta$ chain, and ALDH6A1 mRNAs were found to be increased in metastatic lesions. On the other hand, A1AT and HSP60 mRNAs were found to be decreased (Figure 2).

Validation of surrogate peptides at the protein level. IHC of mPCa involving lymph nodes revealed strong immunoreactivity to ALDH6A1, which was found in areas of perineural invasion in the localized $\mathrm{PCa}$. When metastasis to bone had occurred, ALDH6A1 expression was relatively weaker (Figure 3A). HSP60 was expressed in localized PCa, as well as mPCa (Figure 3B). HSP27 was significantly associated with progressive events, as it was highly expressed in mPCa (Figure 4A), which implied that HSP27 could be a late onset biomarker. Prohibitin showed a stepwise increase in expression, according to the grade and progression (Figure 4B).

Clinical validation for surrogate biomarker. A total of 98 mPca patients were enrolled. All patients were observed during a mean period of 49 months and divided into 2 groups. The number of deceased patients due to metastatic
Table II. Characteristics of metastatic prostate cancer patients.

\begin{tabular}{lcccc}
\hline Variable & $\begin{array}{c}\text { Alive } \\
(\mathrm{N}=50)\end{array}$ & $\begin{array}{c}\text { Deceased } \\
(\mathrm{N}=48)\end{array}$ & $\begin{array}{c}\text { Total } \\
(\mathrm{N}=98)\end{array}$ & $p$-Value \\
\hline Age (years) & 70.5 & 75.1 & 72.8 & $\begin{array}{l}0.0003 \\
\text { Gleason score }\end{array}$ \\
6 & $9(18 \%)$ & $6(12.5 \%)$ & $15(15.3 \%)$ & \\
7 & $23(46 \%)$ & $23(48 \%)$ & $46(46.9 \%)$ & \\
8 & $14(28 \%)$ & $5(10.5 \%)$ & $19(19.4 \%)$ & \\
9 & $4(8 \%)$ & $14(29 \%)$ & $18(18.4 \%)$ & \\
\hline
\end{tabular}

cancer were 38 and mean overall survival was 38 months. Each patient was evaluated according to age, Gleason score and survival (Table II). In the univariate logistic regression analysis when patients were divided into low-intensity staining and high-intensity staining groups, HSP27, ALDH6A1 and prohibitin showed significant differences; however, HSP60 did not show significant differences (Table III; $p<0.001)$. HSP27, ALDH6A1 and prohibitin were concluded to be a triple candidate marker (Figure 5). A random forest analysis that was carried out using these 4 markers indicated that prohibitin had the greatest impact on the significance of variables followed by ALDH1, HSP27, HSP60 according to their importance. Based on this result the classification tree and the conditional inference tree model were re-analyzed. When the tree model was generated using 3 markers and excluding the least significant marker 


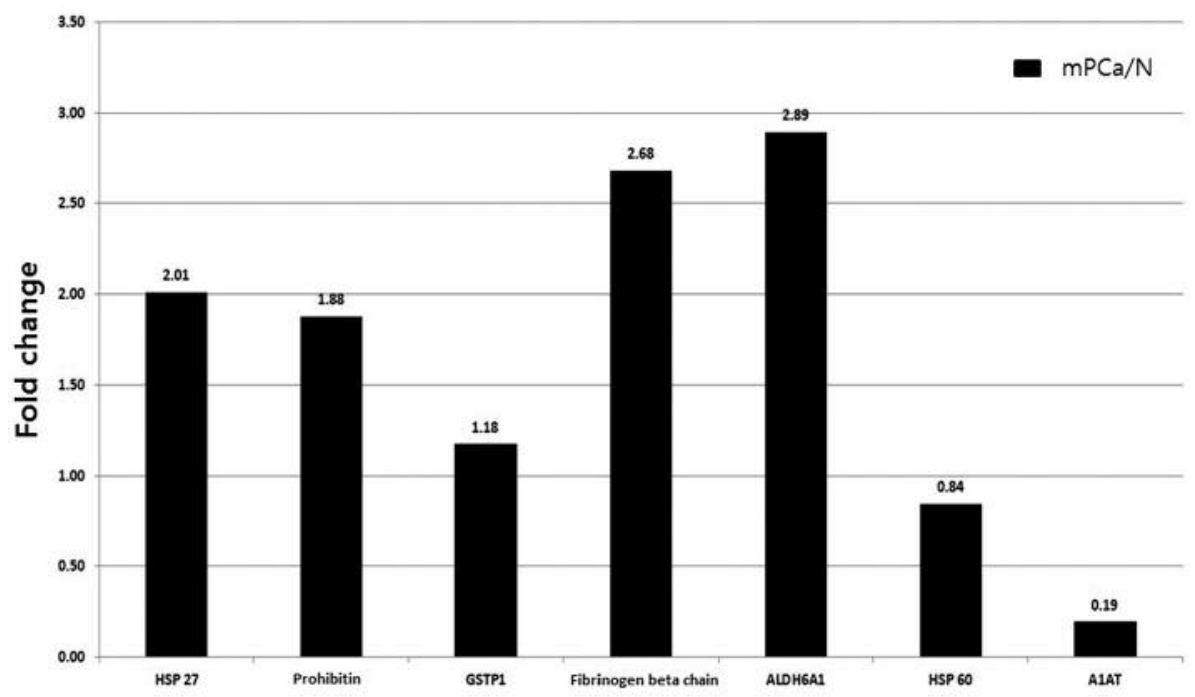

Figure 2. mRNA expression levels of candidate proteins in metastatic prostate cancer tissue compared to normal tissue.

Table III. Univariate logistic regression model after stepwise procedure for candidate markers according to intensity of IHC staining.

\begin{tabular}{|c|c|c|c|c|c|c|}
\hline \multirow{2}{*}{$\begin{array}{l}\text { Intensity of } \\
\text { staining }\end{array}$} & \multirow{2}{*}{$\begin{array}{c}\text { Alive } \\
(\mathrm{N}=50)\end{array}$} & \multirow{2}{*}{$\begin{array}{l}\text { Death } \\
(\mathrm{N}=48)\end{array}$} & \multicolumn{2}{|c|}{ Unadjusted } & \multicolumn{2}{|c|}{ Adjusted for age } \\
\hline & & & OR $(95 \% \mathrm{CI})$ & $p$-Value & OR $(95 \% \mathrm{CI})$ & $p$-Value \\
\hline HSP27 & & & $4.50(1.58-14.91)$ & 0.007 & $1.165(1.08-1.27)$ & $<0.001$ \\
\hline Low & $45(90 \%)$ & $32(66.7 \%)$ & & & & \\
\hline High & $5(10 \%)$ & $16(33.3 \%)$ & & & & \\
\hline HSP60 & & & $0.72(0.31-1.64)$ & 0.434 & $1.156(1.07-1.26)$ & 0.001 \\
\hline Low & $16(32 \%)$ & $19(39.6 \%)$ & & & & \\
\hline High & $34(68 \%)$ & $29(60.4 \%)$ & & & & \\
\hline Prohibitin & & & $4.69(2.03-11.32)$ & $<0.001$ & $1.14(1.06-1.25)$ & 0.001 \\
\hline Low & $36(72 \%)$ & $17(35.4 \%)$ & & & & \\
\hline High & $14(28 \%)$ & $31(64.6 \%)$ & & & & \\
\hline ALDH6A1 & & & $0.10(0.02-0.32)$ & $<0.001$ & $1.147(1.06-1.26)$ & 0.002 \\
\hline Low & $3(6.0 \%)$ & $19(39.6 \%)$ & & & & \\
\hline High & $47(94 \%)$ & $29(60.4 \%)$ & & & & \\
\hline
\end{tabular}

HSP60, the error rate was $17.3 \%$ (Accuracy=82.7\%) and it showed high predictability with 0.826 of AUC (Figure 5).

The AUC of the model generated by categorizing 3 proteins appeared in the tree model statistically significantly higher than the AUC of the model of prohibitin only, prohibitin+HSP27, and prohibitin+ALDH6A1 but the latter was not statistically significantly different ( $p=0.0504)$ (Figure 6).

\section{Discussion}

Currently, only PSA, is the most widely accepted biomarker although often fails detection. The after-PSA project is focused on the discovery of a metastatic or hormonal refractory PCa biomarker. Despite many attempts prior to this study, no available surrogate biomarkers have been found to predict a progressive metastatic course. Here, we provided data indicating that a surrogate trio of biomarkers, namely HSP27, ALDH1 and prohibitin, can provide a metastatic signature.

HSP27 is highly induced by cellular stress, including mitogens, inflammatory cytokines, growth factors, hormones, oxidative stress, and anticancer agents (12). HSP27 expression is correlated with clinical PCa progression, with the highest expression found in metastatic PCa (13). HSP expression independently predicts clinical outcome in prostate cancer (14). Recently, Voll et al. 


\section{A. ALDH6A1}

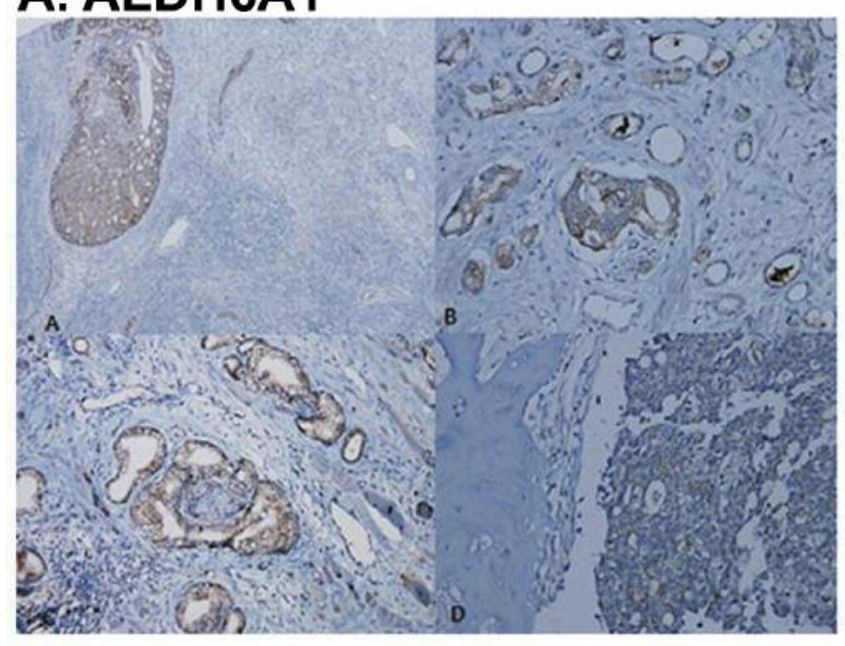

\section{B. HSP60}

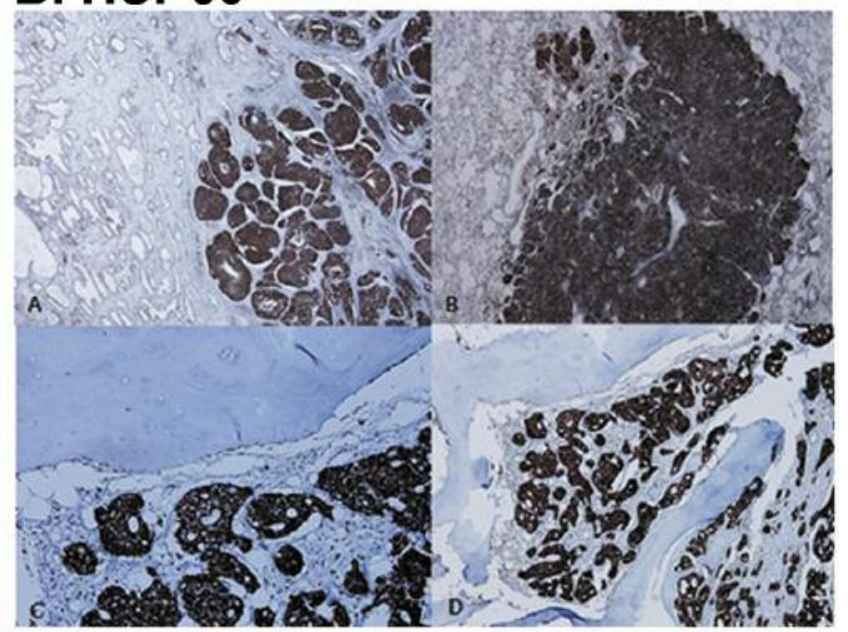

Figure 3. Immunohistochemical expression of ALDH6A1 and HSP60 in prostate cancer. A. ALDH6A1 is expressed in highly aggressive prostate cancers. A) Lymph node prostate cancer metastatic lesions showed specifically strong immunoreactivity to ALDH6A1. B) Invasive prostate cancers from individual glands, Gleason grade 3, demonstrated ALDH6A1 expression in tumor cytoplasm and membrane. C) Prostate cancers of acinar type embrace around the nerve bundle and perineural invasion were positive for ALDH6A1 expression. D) Metastatic prostate cancer to bone was weakly positive for ALDH6Al expression. B. HSP60 was specifically and highly expressed in both primary and metastatic prostate cancer. IHC revealed no difference in HSP60 expression between primary and metastatic prostate cancer. A) HSP60 was restricted to prostate cancer in the radically prostatectomized tissue. B) Lung metastasis of prostate cancer revealed overexpression of HSP60. C-D) Bone prostate cancer metastatic lesions showed intense selective staining to tumors, without exception.

\section{A. HSP27}

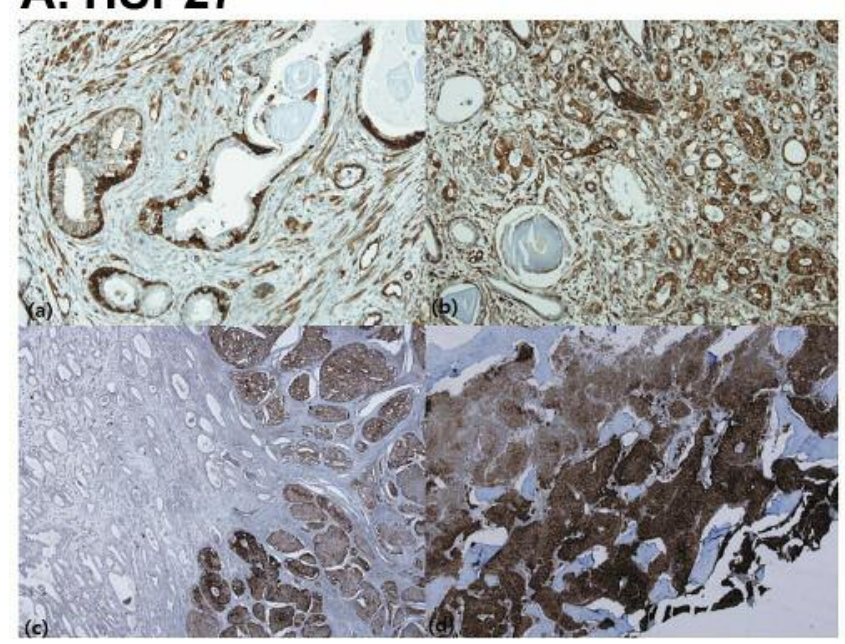

\section{B. Prohibitin}

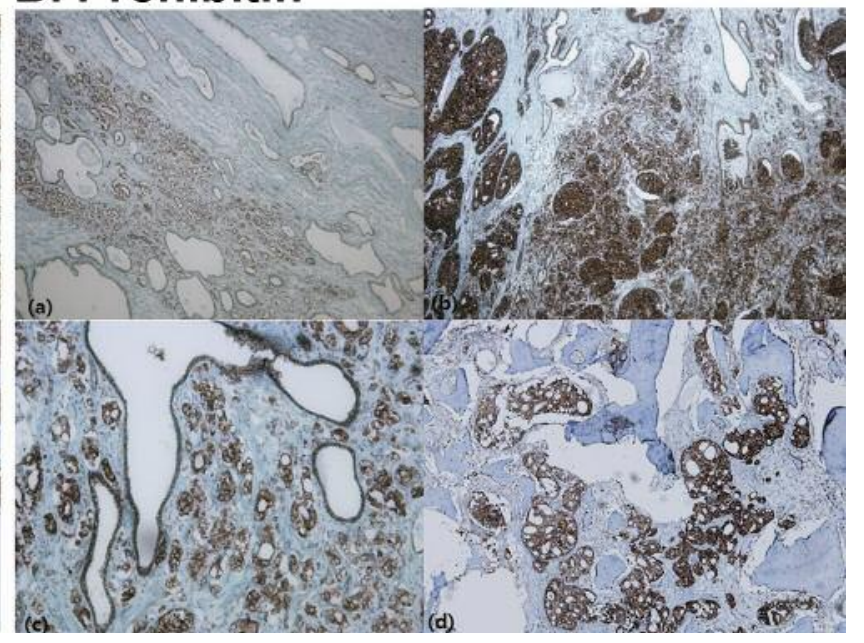

Figure 4. Immunohistochemical expression of HSP27 and prohibitin in prostate cancer. A. HSP27 was only present in metastatic tissues. A-a) Staining is restricted to basal cells in the normal prostate gland. b) Low-grade Pca showed positive cytoplasmic staining along the infiltrating tumor cells. C) Ductal variants of solid growth of high-grade Pca demonstrated intense and diffuse staining. d) Pca metastasizing to the bone showed very strong staining. The HSP27 staining intensity and area increased as tumors progressed. Bone metastasis of prostate cancer showed strong immunoreactivity to HSP27. B. Prohibitin expression positively correlated with prostate cancer tumor grade. B-a) Low-grade Pca showed light staining along the aggregates of small acinars. $B$ - $b$ ) Ductal variants of solid growth of high-grade Pca demonstrated very intense staining. $B-c)$ Higher magnification of localized low grade Pca showed positive reaction to prohibitin. Notice the sparing zone of normal ducts. B-d) Pca metastasizing to the bone also showed very strong and heavy staining to prohibitin. 


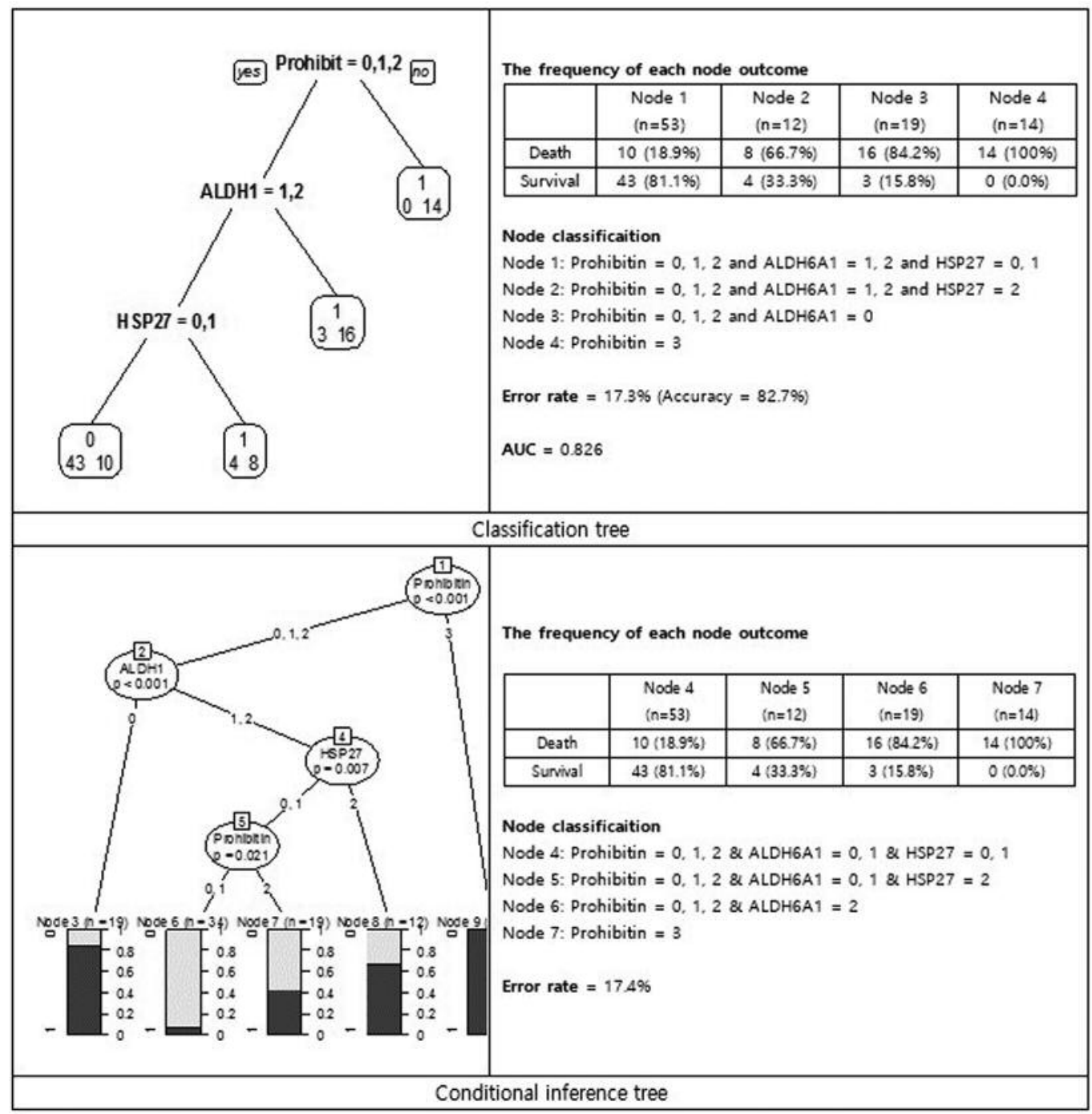

Figure 5. Classification tree and conditional inference tree - Model: 3 Proteins (Prohibitin, ALDH6A1, HSP27).

demonstrated for the first time that HSP27 increased migration of human PCa cells out of the prostate gland resulting in the formation of distant metastasis (15). HSP27 appeared to be strongly associated with metastasis in the present study. Since higher expression was observed in bone metastatic lesions than incipient cancer lesions, it can be used as a strong marker of metastatic cancer. Also, high staining intensity of HSP27 was associated with a poor prognosis of patients with metastatic prostate cancer.

Previously, prohibitin was found to be down-regulated by androgen treatment. Prohibitin is known as a tumor suppressor, mediating $\mathrm{G}_{1} / \mathrm{S}$ arrest and E2F-mediated apoptosis. In addition, it represses ligand dependent androgen receptor (AR) activity and inhibits androgen- stimulated prostate cancer growth in vitro (16). A decrease in prohibitin expression associated with a reduction in the threshold of androgen receptor activity and stimulation of the progression of castration-resistant prostate cancer in vitro and in vivo $(17,18)$. Prohibitin knockdown increased LNCaP (androgen-sensitive human PCa cell line derived from a left supraclavicular lymph node metastasis) cell growth in response to testicular and adrenal androgens (19).

However, unlike previous studies showing that prohibitin expression suppresses prostate cancer, our findings show that prohibitin expression is higher in prostate cancer compared to normal cells (Figure 2). Also, this expression was stronger in higher-grade than in lower-grade cancers, and was stronger in metastatic prostate cancer than in localised cancers (Figure 4B). 


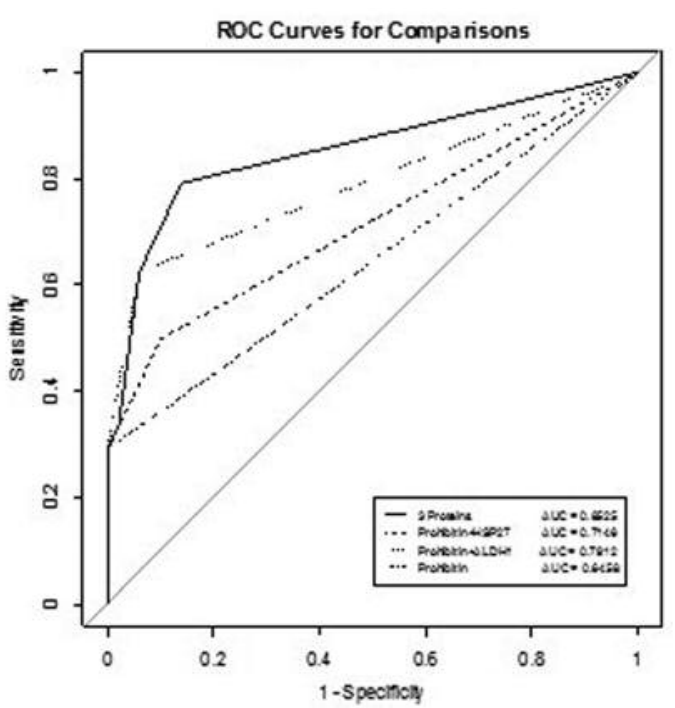

\begin{tabular}{|l|c|c|}
\hline \multicolumn{1}{|c|}{ Model } & AUC & $p$-Value \\
\hline $\begin{array}{l}\text { Model 1: } \\
\text { Prohibitin+HSP27+ALDH6A1 }\end{array}$ & 0.8525 & - \\
\hline Model 2: Prohibitin & 0.6458 & $\begin{array}{c}1 \text { vs. } 2 \\
<0.0001\end{array}$ \\
\hline Model 3: Prohibitin+HSP27 & 0.7146 & $\begin{array}{l}1 \text { vs. } 2 \\
0.0002\end{array}$ \\
\hline Model 4: Prohibitin+ALDH6A1 & 0.7912 & $\begin{array}{l}1 \text { vs. } 2 \\
0.0168\end{array}$ \\
\hline
\end{tabular}

Figure 6. ROC curves and AUC for last model and proteins.

The connection between prohibitin and prostate cancer was further illustrated by another recent study, which revealed that prohibitin participates in Transforming Growth Factor- $\beta$ (TGF- $\beta$ ) signaling in prostate cancer cells (20). TGF- $\beta$ acts as a tumor suppressor in prostate tissues by inducing apoptosis and repressing cell proliferation in normal prostate epithelium. Conversely, TGF- $\beta$ promotes tumor progression and metastasis in tumor cells by inducing cell invasion and enhancing angiogenesis and immunosuppression. Subsequent investigation revealed that prohibitin was exported from the nucleus in response to TGF- $\beta$ (20). Thus, prohibitin is a potential effector of TGF- $\beta$ signaling and could be associated with tumor progression and metastasis.

Our results indicate that prohibitin affects tumor progression and invasion in metastatic PCa and may also be explained by these recent studies.

In addition, two other proteins, HSP60 and ALDH were previously found to be valuable for predicting a poor prognosis. HSP60 overexpression was observed in early stages of prostate carcinogenesis. Recently, HSP60 expression was correlated to a high Gleason score, biochemical recurrence and lymph node metastasis $(21,22)$. Similarly, in our study, HSP60 was increased in both incipient and metastatic lesions of prostate cancer. It is expected to be used as a candidate marker because increased mRNA expression was associated with metastasis. However, it may not be used as a factor to classify metastatic lesions because an increased, but not statistically different, expression was observed in incipient focus and metastatic bone and lung lesions.

ALDH1 expression correlates with epithelial tumor cell prognosis; however, it is unknown which isoform might be responsible (23). ALDH7A1 was proposed to play a role in bone metastasis in $\mathrm{mPCa}$ (24). This gene encodes a member of the aldehyde dehydrogenase protein family. The encoded protein is a mitochondrial methylmalonate semialdehyde dehydrogenase that plays a role in the valine and pyrimidine catabolic pathways. This protein catalyzes the irreversible oxidative decarboxylation of malonate and methylmalonate semialdehydes to acetyl- and propionyl-CoA (25). In the present study, ALDH6A1 overexpression was significantly associated with lymphatic invasion in PCa. In case of ALDH1, it is widely known that there is a correlation with cancer (23). In the present study, ALDH6A1 showed strong positive reaction in incipient prostate cancer, lymph node metastasis, nerve metastasis, but it showed weak positive reaction in bone metastasis.

\section{Conclusion}

Our study demonstrated that the trio marker model is the most reliable method to predict metastatic prostate cancer and progression. Clinical trial data are needed to further explore clinical significance.

\section{Conflicts of Interest}

The Authors declare no conflicts of interest regarding this study.

\section{Acknowledgements}

This study was supported by the Mid-Career Researcher Program through a National Research Foundation of Korea grant (No.2016R1A2B4011115; CNH).

\section{References}

1 Wallace TJ, Torre T, Grob M, Yu J, Avital I, Brücher B, Stojadinovic A and Man YG:Current approaches, challenges and future directions for monitoring treatment response in prostate cancer. J Cancer 5(1): 3-24, 2014.

2 Mohammed AA: Biomarkers in prostate cancer: new era and prospective. Med Oncol 31(8): 140, 2014.

3 Heidenreich A, Bellmunt J, Bolla M, Joniau S, Mason M, Matveev V, Mottet N, Schmid HP, van der Kwast T, Wiegel T and Zattoni F: EAU guidelines on prostate cancer. Part 1: screening, diagnosis, and treatment of clinically localised disease. Eur Urol 59(1): 61-71, 2011. 
4 Sumey C and Flaig TW: Adjuvant medical therapy for prostate cancer. Expert Opin Pharmacother 12(1): 73-84, 2011.

5 Bradford MM: A rapid and sensitive method for the quantitation of microgram quantities of protein utilizing the principle of protein-dye binding. Anal Biochem 72: 248-254, 1976.

6 Rabilloud T, Kieffer S, Procaccio V, Louwagie M, Courchesne PL, Patterson SD, Martinez P, Garin J and Lunardi J: Twodimensional electrophoresis of human placental mitochondria and protein identification by mass spectrometry: toward a human mitochondrial proteome. Electrophoresis 19(6): 1006-1014, 1998.

7 Fernandez J, Gharahdaghi $\mathrm{F}$ and Mische SM: Routine identification of proteins from sodium dodecyl sulfatepolyacrylamide gel electrophoresis (SDS-PAGE) gels or polyvinyl difluoride membranes using matrix assisted laser desorption/ionization-time of flight-mass spectrometry (MALDITOF-MS). Electrophoresis 19(6): 1036-1045, 1998.

8 Flensburg $\mathrm{J}$ and Belew M: Characterization of recombinant human serum albumin using matrix-assisted laser desorption ionization time-of-flight mass spectrometry. J Chromatogr A 1009(1-2): 111-117, 2003

9 Wang D, Kalb SR and Cotter RJ: Improved procedures for Nterminal sulfonation of peptides for matrix-assisted laser desorption/ionization post-source decay peptide sequencing. Rapid Commun Mass Spectrom 18(1): 96-102, 2004.

10 Geiss GK, Bumgarner RE, Birditt B, Dahl T, Dowidar N, Dunaway DL, Fell HP, Ferree S, George RD, Grogan T, James JJ, Maysuria M, Mitton JD, Oliveri P, Osborn JL, Peng T, Ratcliffe AL, Webster PJ, Davidson EH, Hood L and Dimitrov K: Direct multiplexed measurement of gene expression with color-coded probe pairs. Nat Biotechnol 26(3): 317-325, 2008.

11 Mairinger FD, Walter RF, Werner R, Christoph DC, Ting S, Vollbrecht C, Zarogoulidis K, Huang H, Li Q, Schmid KW, Wohlschlaeger $\mathrm{J}$ and Zarogoulidis P: Activation of angiogenesis differs strongly between pulmonary carcinoids and neuroendocrine carinomas and is crucial for carcinoid tumourgenesis. J Cancer 5(6): 465-471, 2014.

12 Zoubeidi A and Gleave M: Small heat shock proteins in cancer therapy and prognosis. Int J Biochem Cell Biol 44(10): 16461656, 2012.

13 Foster CS, Dodson AR, Ambroisine L, Fisher G, Møller H, Clark J, Attard G, De-Bono J, Scardino P, Reuter VE, Cooper CS, Berney DM and Cuzick J: Hsp-27 expression at diagnosis predicts poor clinical outcome in prostate cancer independent of ETS-gene rearrangement. Br J Cancer 101(7): 1137-1344, 2009.

14 Cornford PA, Dodson AR, Parsons KF, Desmond AD, Woolfenden A, Fordham M, Neoptolemos JP, Ke Y and Foster CS: Heat shock protein expression independently predicts clinical outcome in prostate cancer. Cancer Res 60(24): 7099$7105,2000$.
15 Voll EA, Ogden IM, Pavese JM, Huang X, Xu L, Jovanovic BD and Bergan RC: Heat shock protein 27 regulates human prostate cancer cell motility and metastatic progression. Oncotarget 5(9): 2648-2663, 2014.

16 Gamble SC, Chotai D, Odontiadis M, Dart DA, Brooke GN, Powell SM, Reebye V, Varela-Carver A, Kawano Y, Waxman J and Bevan CL: Prohibitin, a protein downregulated by androgens, represses androgen receptor activity. Oncogene 26(12): 1757-1768, 2007.

17 Jenster G: The role of the androgen receptor in the development and progression of prostate cancer. Semin Oncol 26(4): 407-421, 1999.

18 Dart DA, Brooke GN, Sita-Lumsden A, Waxman J and Bevan CL: Reducing prohibitin increases histone acetylation, and promotes androgen independence in prostate tumours by increasing androgen receptor activation by adrenal androgens. Oncogene 31(43): 4588-4598, 2012.

19 Zhu B, Fukada K, Zhu H and Kyprianou N: Prohibitin and cofilin are intracellular effectors of transforming growth factor beta signaling in human prostate cancer cells. Cancer Res 66(17): 8640-8647, 2006.

20 Wang S and Faller DV: Roles of prohibitin in growth control and tumor suppression in human cancers. Transl Oncogenomics 3: 23-37, 2008.

21 Glaessgen A, Jonmarker S, Lindberg A, Nilsson B, Lewensohn R, Ekman P, Valdman A and Egevad L: Heat shock proteins 27, 60 and 70 as prognostic markers of prostate cancer. APMIS 116(10): 888-895, 2008.

22 Castilla C, Congregado B, Conde JM, Medina R, Torrubia FJ, Japón MA and Sáez C: Immunohistochemical expression of Hsp60 correlates with tumor progression and hormone resistance in prostate cancer. Urology 76(4): 1017.e1-e6, 2010.

23 Huang EH, Hynes MJ, Zhang T, Ginestier C, Dontu G, Appelman H, Fields JZ, Wicha MS and Boman BM: Aldehyde dehydrogenase 1 is a marker for normal and malignant human colonic stem cells (SC) and tracks SC overpopulation during colon tumorigenesis. Cancer Res 69(8): 3382-3389, 2009.

24 van den Hoogen C, van der Horst G, Cheung H, Buijs JT, Pelger RC and van der Pluijm G: The aldehyde dehydrogenase enzyme 7A1 is functionally involved in prostate cancer bone metastasis. Clin Exp Metastasis 28(7): 615-625, 2011.

25 Gene ID: 4329, updated on 4-Jun-2017, https://www.ncbi.nlm. nih.gov/gene/4329. 